\title{
0 EDITOR'S CHOICE \\ Attempted and completed suicides after subthalamic nucleus stimulation for Parkinson's disease
}

\author{
T Soulas, ${ }^{1,2}$ J-M Gurruchaga, ${ }^{1}$ S Palfi, ${ }^{1}$ P Cesaro, ${ }^{2}$ J-P Nguyen, ${ }^{1}$ G Fénelon ${ }^{2}$
}

\section{See Editorial Commentary, p 851}

${ }^{1}$ AP-HP, CHU Henri Mondor, Department of Neurosurgery, Créteil, France; ${ }^{2} \mathrm{AP}-\mathrm{HP}, \mathrm{CHU}$ Henri Mondor, Department of Neurology, Créteil, France

Correspondence to: Dr G Fénelon, Department of Neurology, CHU Henri Mondor, 94000-Créteil, France; gilles.fenelon@aphp.hmn.fr

Received 20 July 2007 Revised 25 March 2008 Accepted 26 March 2008 Published Online First 10 April 2008

\begin{abstract}
A higher than expected frequency of suicide has been reported among patients undergoing subthalamic nucleus deep brain stimulation (STN DBS) for advanced

Parkinson's disease (PD). We conducted a retrospective survey of 200 patients with PD who underwent STN DBS. Two patients (1\%) committed suicide and four (2\%) attempted suicide, despite clear motor improvements. Suicidal patients did not differ from non-suicidal patients with respect to age, disease duration or preoperative depressive and cognitive status. Suicidal behaviour was associated with postoperative depression and/or altered impulse regulation. Suicidal behaviour is a potential hazard of STN DBS, calling for careful preoperative assessment and close postoperative psychiatric and behavioural follow-up.
\end{abstract}

Despite a high frequency of depression, the incidence of suicide among patients with Parkinson's disease (PD) is similar to ${ }^{1}$ or 10 times lower than that recorded in the general population. ${ }^{2}$ Recently, concerns have been raised about a higher than expected frequency of suicide among patients undergoing subthalamic nucleus deep brain stimulation (STN DBS) for advanced PD. ${ }^{34}$ We therefore examined the prevalence and characteristics of completed and attempted suicides in a large cohort of patients who underwent STN DBS in our centre.

\section{METHODS}

We reviewed the files of all 200 patients with PD (127 men and 73 women; mean age 61.8 (8.6) years; disease duration 14.8 (4.8) years) who underwent bilateral STN DBS in our centre between 1997 and 2006. During the study period, 24 patients died. There were two suicides, two deaths in undetermined circumstances and one death by defenestration 3 days after surgery. This latter patient was in a postoperative confusional state and the stimulator had not yet been switched on; we considered that death was more likely accidental than intentional and did not include this case among the suicides. Six patients were monitored in other centres, for geographic reasons, and 12 patients were lost to follow-up (possibly following unreported death). At the end of the study period, all of the remaining 158 patients were followed-up in our centre by the same neurologist (J-MG). STN DBS was performed under local or general anaesthesia. STN coordinates were calculated from preoperative MRI and intraoperative ventriculographic data and were confirmed by intraoperative recording of neuronal activity with semi-microelectrodes and turn amplitude analysis. Scores on the Mattis Dementia Rating Scale (MDRS, maximum score 144) and the Montgomery-Asberg Depression Scale (MADRS, maximum score 60) were compared with a t test between suicidal patients and the last 75 consecutive non-suicidal patients who had undergone the same preoperative assessment of depression. All patients who attempted suicide were interviewed by a psychologist (TS).

\section{RESULTS}

Two patients (1\%) committed suicide and four patients (2\%) attempted suicide, a mean 12.0 (7.2) months after surgery, despite fair to excellent motor improvement. Attempted and completed suicides occurred between 2002 and 2006. Details of the six suicidal patients are given in table 1 . No suicides occurred among waiting list patients. Compared with the 75 non-suicidal patients, the suicidal patients did not differ significantly with respect to age (61.6 (7.8) vs 60.7 (7.5) years), disease duration (13.0 (4.3) vs 11.7 (4.5) years), MDRS score (133.7 (6.9) vs 135.0 (4.5)) or MADRS score (9.5 (5.7) vs $11.4(8.9))$. No link was found between suicide and recent changes in stimulator settings. Three of the four patients who attempted suicide did not really endanger their life, and all tended to minimise their actions. These three patients took a drug overdose while under considerable mental pressure, and none had a history of compulsive medication or overdose. Two illustrative cases are described.

\section{Patient No 1 (completed suicide)}

STN DBS yielded a major motor improvement and allowed a reduction in dopaminergic treatment. The patient was found to have a dysthymic state about 3 months after surgery and was prescribed citalopram. At this time he said he had taken an overdose of Sinemet following an episode of erectile dysfunction, although this could not be confirmed. In the following weeks his mood clearly improved, he had several projects and he resumed his cycling hobby. A few days before the suicide his psychiatrist had scheduled a reduction in his antidepressant treatment during the following weeks. On the evening of his death, the patient and his wife had friends to dinner; the only noteworthy incident was that the patient complained of difficulty in eating his seafood. At the end of the meal, he took his evening drugs, prepared those for the following morning, set his alarm clock and went to bed. Half an hour later he got up in haste, went through the house silently, locked his wife and guests indoors, and left. He was last seen running through the street in the 
Table 1 Characteristics of the suicidal patients

\begin{tabular}{|c|c|c|c|c|c|c|}
\hline & \multicolumn{2}{|c|}{ Completed suicides } & \multicolumn{4}{|c|}{ Attempted suicides } \\
\hline & Patient No 1 & Patient No 2 & Patient No 3 & Patient No 4 & Patient No 5 & Patient No 6 \\
\hline Sex & M & $\mathrm{F}$ & $\mathrm{F}$ & M & M & $\mathrm{F}$ \\
\hline Age at DBS (y) & 67 & 55 & 58 & 50 & 65 & 69 \\
\hline PD duration at DBS (y) & 8 & 11 & 8 & 14 & 10 & 19 \\
\hline $\begin{array}{l}\text { UPDRS III (score) off medication: pre-DBS/post-DBS, } \\
\text { on stimulation ( } \% \text { reduction)* }\end{array}$ & $33 / 23(30)$ & $80 / 24(70)$ & $37 / 19(49)$ & $58 / 16(72)$ & $66 / 26(61)$ & $67 / 23(66)$ \\
\hline $\begin{array}{l}\text { Levodopa equivalent daily dosage }(\mathrm{mg}) \text { : pre-DBS/post- } \\
\text { DBS (\% reduction)* }\end{array}$ & $2400 / 455(81)$ & $1960 / 0(100)$ & $1400 / 300(79)$ & $\begin{array}{l}1280 / 1040 \\
(19)\end{array}$ & $5130 / 1375(73)$ & $970 / 350(64)$ \\
\hline \multicolumn{7}{|l|}{ Parameters of stimulation* } \\
\hline Contact (right/left) & $2 / 6$ & $2 / 7$ & $3 / 6$ & $3 / 6$ & $2 / 6$ & $2 / 6$ \\
\hline Voltage (V, right/left) & $2.8 / 2.1$ & $2.8 / 2.2$ & $2.8 / 3.4$ & $1.8 / 2.0$ & $4.1 / 4.4$ & $2.1 / 2.3$ \\
\hline Frequency (Hz, right/left) & $160 / 160$ & $160 / 160$ & $130 / 130$ & $130 / 130$ & $150 / 150$ & $130 / 130$ \\
\hline Pulse width ( $\mu \mathrm{s}$, right/left) & $90 / 90$ & $90 / 120$ & $90 / 90$ & $90 / 90$ & $90 / 90$ & $90 / 90$ \\
\hline Time between DBS and suicidal behaviour (months) & 5 & 24 & 14 & 6 & 15 & 8 \\
\hline Pre-DBS psychiatric features & - & $\begin{array}{l}\text { Personality disorder, } \\
\text { depression, delusions }\end{array}$ & - & - & $\begin{array}{l}\text { Pathological } \\
\text { gambling, } \\
\text { hypersexuality, } \\
\text { paedophilia }\end{array}$ & $\begin{array}{l}\text { Depression, } \\
\text { hallucinations on } \\
\text { dopaminergic } \\
\text { agonists }\end{array}$ \\
\hline Family history & PD, suicides & PD & - & - & - & - \\
\hline Pre-DBS suicide attempts & No & Yes $(n=1)$ & No & No & No & Yes $(n=2)$ \\
\hline Psychiatric features at time of suicide & - & Depression, delusions & $\begin{array}{l}\text { Depression, } \\
\text { delusions }\end{array}$ & - & Depression & Depression \\
\hline Setting/apparent trigger & $\begin{array}{l}\text { Home,/mild } \\
\text { annoyance }\end{array}$ & $\begin{array}{l}\text { Hospital (left } \\
\text { surreptitiously)/none }\end{array}$ & Hospital/none & $\begin{array}{l}\text { Home/familial } \\
\text { conflict }\end{array}$ & $\begin{array}{l}\text { Home/prosecution } \\
\text { in paedophilia case }\end{array}$ & $\begin{array}{l}\text { Home/marital } \\
\text { conflict }\end{array}$ \\
\hline Method of suicide & Drowning & Drowning & $\begin{array}{l}\text { Attempted } \\
\text { defenestration }\end{array}$ & $\begin{array}{l}\text { Alcohol and } \\
\text { drug overdose }\end{array}$ & $\begin{array}{l}\text { Alcohol and drug } \\
\text { overdose }\end{array}$ & Drug overdose \\
\hline
\end{tabular}

*Post-DBS data from the last evaluation before suicide.

DBS, deep brain stimulation; PD, Parkinson's disease; UPDRS III, Unified Parkinson's Disease Rating Scale, part III (motor examination).

direction of a nearby beach. His spouse alerted the police but his body was discovered $1 \mathrm{~h}$ later on the beach; he had died from drowning.

\section{Case No 5 (attempted suicide)}

Prior to surgery this patient had episodes of hypersexuality (including undisclosed paedophile behaviour), pathological gambling and a tendency to L-dopa addiction. These impulse control disorders improved after a reduction in dopaminergic treatment. A few months after surgery the patient developed a depressive state. He also had several abrupt reactions, such as running home from our ward while the stimulation parameters were being set. He attempted suicide 15 months after surgery, and later made three other attempts using drugs and alcohol at almost the same doses.

\section{DISCUSSION}

The prevalence of completed (1\%) and attempted (2\%) suicide after STN DBS was higher than expected in this series. The prevalence rate of suicide in the French population of the same age (between 45 and 74 years) is approximately $16 / 10^{5}$ for women and from 37 to $50 / 10^{5}$ for men. ${ }^{5}$ The two completed suicides observed here both involved drowning, whereas the most frequent methods recorded in the general French population of the same age are shooting and hanging. ${ }^{6}$ Other cases of attempted and completed suicide have been reported following STN DBS. ${ }^{3}{ }^{7-11}$ In a recent large prospective multicentre study of 5025 patients undergoing STN DBS, the rates of completed and attempted suicide were $0.4 \%$ and $0.9 \%$, which are again far higher than in the general population. ${ }^{4}$

Suicide is commonly associated with depression in patients with PD after STN DBS, as in the general population. ${ }^{12}$ Four of our six suicidal patients were depressed. Voon and colleagues ${ }^{4}$ found that postoperative depression after STN-DBS was a major risk factor for suicide. Transient or chronic depression has been reported to affect up to $25 \%$ of patients following STN DBS. ${ }^{13}$ The origin of this postoperative depression is unclear and may be multifactorial. ${ }^{8}{ }^{14}$ Risk factors may include a history of mood disorders, and psychological factors such as poor tolerance of the adverse effects of STN DBS (hypophonia, eyelid apraxia, etc), disappointment with the results of STN DBS or difficulties adjusting to familial or socio-professional life. A reduction in dopaminergic treatment may also play a part (our case No 2, see Houéto and colleagues ${ }^{7}$ ), suggesting that, at least in patients with pre-DBS mood disorder, dopaminergic drugs should not be abruptly reduced postoperatively. Finally, DBS itself may have a direct effect on mood. Severe but reversible depression has been noted on activating the stimulator, when the stimulating plot was located not within the STN but in the substantia nigra ${ }^{15}$ or the zona incerta. ${ }^{16}$ STN DBS has also been followed by onset of mania or hypomania in the months following surgery. ${ }^{13}$

Postoperative depression does not appear to explain the observed rate of suicide, however. Firstly, as already mentioned, although depression is frequent in $\mathrm{PD}$, the rate of suicide is low; secondly, some suicides after STN-DBS are not clearly associated with depression, as in our patient Nos 2 and 5, and in other series (patient No 4 in Burkhard and colleagues ${ }^{3}$ ). Other potential risk factors include altered impulse regulation and/or an inability to control emotions. Increased impulsiveness was probably a major factor in the suicidal behaviour of some of our patients, as illustrated by case No 1 . The possible impact of STN DBS on impulse control is not clearly established. In some cases, impulse control disorders such as pathological gambling ${ }^{17}$ and dopaminergic drug addiction ${ }^{18}$ can be improved by STN DBS, probably through the reduction in dopaminergic treatment. Lhommée and colleagues ${ }^{19}$ found that, in patients with PD off medication, STN DBS did not globally induce impulsiveness in the Rogers decision making test or on the Barratt self-rating 
scale, although it did induce premature responses in the interference part of the Stroop test, suggesting defective executive inhibition. However, Frank et al recently showed that STN DBS selectively interferes with the normal ability to slow down when faced with decision conflict. ${ }^{20}$ In contrast, impulse control disorders such as pathological gambling ${ }^{21}$ and hypersexuality ${ }^{22}$ may occur de novo following surgery. Impulsive aggressive behaviours have also been reported following STN $\mathrm{DBS},{ }^{82}$ as well as aggressive behaviour induced by intraoperative stimulation of the posterior hypothalamic area. ${ }^{25}$ Our patients did not display such aggressive behaviours but, in keeping with previous observations, ${ }^{7}$ some of them had stronger emotional reactivity (case Nos 1, 3 and 4). A possible effect of STN DBS on impulsivity suggests that these patients need careful postoperative setting of the electrical parameters, along with close psychiatric follow-up.

Finally, it should be emphasised that suicides have also been reported following pallidal or thalamic DBS in patients with PD and other conditions, such as dystonia. ${ }^{3} 6$ This further suggests that an induced disturbance of the basal ganglia circuitry, presumably in the limbic component, may induce mood disorders and/or suicidal ideas.

The main limitation of our study is its retrospective nature. We cannot rule out the possibility that some suicide attempts were not spontaneously disclosed by the patients or their caregivers, especially during the early years of the study period, before attention was drawn to the risk of postoperative behavioural changes. It is also possible that some patients who were lost to follow-up attempted suicide. However, the effect of such biases would be to underestimate the real prevalence of suicide in this setting, and would thus reinforce the main conclusions of our study.

In conclusion, suicidal behaviour is a serious potential hazard of STN DBS. Although postoperative depression is clearly a risk factor, other factors such as increased impulsiveness may play a part. This risk calls for careful preoperative assessment and for close postoperative psychiatric and behavioural follow-up.

Acknowledgements: We thank David Young for his help in editing the manuscript. Competing interests: None.

\section{REFERENCES}

1. Stenager EN, Wermuth L, Stenager E, et al. Suicide in patients with Parkinson's disease. An epidemiological study. Acta Psychiatr Scand 1994;90:70-2.

2. Myslobodsky M, Lalonde FM, Hicks L. Are patients with Parkinson's disease suicidal? J Geriatr Psychiatry Neurol 2001;14:120-4.
3. Burkhard PR, Vingerhoets FJG, Berney A, et al. Suicide after successful deep brain stimulation for movement disorders. Neurology 2004;63:2170-2.

4. Voon V, Krack P, Lang A, et al. Factors associated with suicide risk following STN DBS for Parkinson's disease. Mov Disord 2006;21(Suppl 15):S691.

5. Philippe A. Epidémiologie des suicides et des tentatives de suicide. Le devenir des tentatives de suicides. In: Lemperrière T, ed. Dépression et suicide. Paris: Acanthe, Masson, 2000:3-21

6. Le Pont F, Letrilliart L, Massari, et al. Suicide and attempted suicide in France: results of a general practice sentinel network, 1999-2001. Br J Gen Pract 2004; 54:282-4.

7. Houéto JL, Mesnage V, Mallet $\mathrm{L}$, et al. Behavioral disorders, Parkinson's disease and subthalamic stimulation. J Neurol Neurosurg Psychiatry 2002;72:701-7.

8. Krack P, Batir A, Van Blercom N, et al. Five-year follow-up of bilateral stimulation of the subthalamic nnucleus in advanced Parkinson's disease. N Engl J Med 2003;349:1925-34.

9. Doshi PK, Chhaya N, Bhatt MH. Depression leading to attempted suicide after bilateral subthalamic nucleus stimulation for Parkinson's disease. Mov Disord 2002;17:1084-5.

10. Kleiner-Fisman G, Fisman DN, Sime E, et al. Long-term follow up of bilateral deep brain stimulation of the subthalamic nucleus in patients with advanced Parkinson's disease. J Neurosurg 2003;99:489-95.

11. Funkiewiez A, Ardouin C, Caputo E, et al. Long term effects of bilateral subthalamic nucleus stimulation on cognitive function, mood, and behavior in Parkinson's disease. J Neurol Neurosurg Psychiatry 2004;75:834-9.

12. Maris RW. Suicide. Lancet 2002;360:319-26

13. Voon V, Kubu C, Krack P, et al. Deep brain stimulation: neuropsychological and neuropsychiatric issues. Mov Disord 2006;21(Suppl 14):S305-27.

14. Schüpbach $\mathbf{M}$, Gargiulo $\mathbf{M}$, Welter ML, et al. Neurosurgery in Parkinson's disease. A distressed mind in a repaired body? Neurology 2006;66:1811-16.

15. Bejjani BP, Damier P, Arnulf I, et al. Transient acute depression induced by highfrequency deep-brain stimulation. N Engl J Med 1999;340:1476-80.

16. Stefurak T, Mikulis D, Mayberg H, et al. Deep brain stimulation for Parkinson's disease dissociates mood and motor circuits: a functional MRI case study. Mov Disord 2003:18:1508-16.

17. Ardouin C, Voon V, Worbe $Y$, et al. Pathological gambling in Parkinson's disease improves on chronic subthalamic nucleus stimulation. Mov Disord 2006:21:1941-6.

18. Witjas T, Baunez C, Henry JM, et al. Addiction in Parkinson's disease: impact of subthalamic nucleus deep brain stimulation. Mov Disord 2005;20:1052-5.

19. Lhommée $\mathbf{E}$, Torny $\mathrm{F}$, Ardouin $\mathrm{C}$, et al. Is the impulsivity concept able to explain behavioral effects of subthalamic nucleus stimulation in Parkinson's disease? Mov Disord 2005:20(Suppl 10):S88.

20. Frank MJ, Samanta J, Moustafa AA, et al. Hold your horses: impusivity, deep brain stimulation, and medication in parkinsonism. Science 2007;318:1309-12.

21. Smeding HMM, Goudriaan AE, Foncke EMJ, et al. Pathological gambling after bilateral STN stimulation in Parkinson disease. J Neurol Neurosurg Psychiatry 2007;78:517-19.

22. Visser-Vandewalle V, Van Der Linden C, Temel $Y$, et al. Long-term effects of bilateral nucleus stimulation in advanced Parkinson's disease: a four year follow-up study. Parkinsonism Relat Disord 2005;11:157-65.

23. Albanese A, Piacentini S, Romito LMA, et al. Suicide after successful deep brain stimulation for movement disorders. Neurology 2005;65:499-500.

24. Sensi M, Eleopra R, Cavallo MA, et al. Explosive-aggressive behavior related to bilateral subthalamic stimulation. Parkinsonism Relat Disord 2004:10:247-51.

25. Bejjani BP, Houeto JL, Hariz M, et al. Aggressive behavior induced by intraoperative stimulation in the triangle of Sano. Neurology 2002;59:1425-7.

26. Foncke EMJ, Schuurman PR, Speelman JD. Suicide after deep brain stimulation of the internal globus pallidus for dystonia. Neurology 2006;66:142-3. 